\title{
AMANDA LABARCA: SU PREOCUPACIÓN POR LA LITERATURA, LA EDUCACIÓN Y LA MUJER ${ }^{1}$
}

\author{
Dr. Jaime Caiceo Escudero \\ Académico de la Universidad de Santiago de Chile \\ jcaiceo@hotmail.com
}

\section{RESUMEN}

Amanda Labarca fue una importante educadora chilena del siglo pasado que se distinguió por su preocupación por el incremento de la educación secundaria en el país, por la educación de las clases más desfavorecidas, por la educación de la mujer y por el acceso de sus compañeras de género al sufragio universal (Caiceo, 2013 ${ }^{\mathrm{a}}$ ). El énfasis en esta ocasión, se centrará en un análisis de las principales obras literarias de la autora para relacionarlas con la educación y la política. Entre ellas sobresalen Impresiones de Juventud con subtítulo La Novela Castellana de Hoy (1909), En tierras extrañas (1915), ¿A dónde va la Mujer? (1934), Desvelos en el Alba (1945), Feminismo contemporáneo (1947), y Una Mujer Enjuicia al Tiempo (1970). A partir de estas obras escritas en un espacio de tiempo de 61 años se podrá entender ese período histórico (1909-1970) en el contexto de la situación de la mujer, quien pasa de estar postergada en la educación sin derechos ciudadanos a una mujer empoderada en la sociedad chilena con una gran participación en el sistema educativo y en la vida política del país.

Palabras claves: La mujer y la educación; La mujer y la política; Igualdad de género; Literatura y derechos de la mujer.

\begin{abstract}
Amanda Labarca was an important Chilean educator of the last century who was distinguished by his concern about the increase in secondary education in the country, the education of the most disadvantaged classes, women's education and her companions of gender access to universal suffrage (Caiceo, 2013a). The emphasis on this occasion will focus on an analysis of the major literacy works of the author to relate them to the education and politics. Do they include Impresiones de Juventud (Impressions of youth) with subtitle La Novela Castellana de Hoy (The novel Spanish today) (1909), En tierras extrañas (In strange lands) (1915), A dónde va la Mujer? (¿Where it goes the woman? (1934), Desvelos en el Alba (Efforts at Alba) (1945), Feminismo contemporáneo (Contemporary feminism) (1947) and Una Mujer Enjuicia al Tiempo (A woman prosecuted at the time (1970). Based on these works, written in a space of 61 years that historical period (1909-1970) will understand in the context of the situation of women, who happens to be delayed in education without citizenship rights a woman empowered in Chilean society with a large participation in the educational system and in the political life of the country.
\end{abstract}

Key words: Women and education/ Women and politics/ / Gender equality/ Literature and women's rights. 


\section{1.- Introducción}

En el contexto historiográfico educativo, Amanda Labarca es vastamente conocida por el señero aporte que realizó a la educación chilena, tanto desde el Ministerio de Educación como desde la Universidad de Chile. También su preocupación por la reivindicación de derechos para la mujer en el plano educativo y político (Caiceo, 2013). Sin embargo, que como profesora de castellano, en sus escritos literarios, aborde directamente el tema, inspirándose en los grupos de avanzada que en su época existían sobre esta temática, es menos conocido.

El objetivo de este Artículo es abordar, justamente ese aspecto. En el punto siguiente, se entregarán algunos antecedentes biográficos sobre la autora; luego, a fin de contextualizar el problema a desarrollar, se indicarán los aspectos sociales y culturales más relevantes de Chile desde fines del siglo XIX a comienzos del siglo XX, para luego analizar en sus escritos su preocupación preferente por los derechos de la mujer, tanto en lo educacional como en lo político.

\section{2.- Algunos Antecedentes Biográficos de Amanda Labarca}

Amanda Pinto Sepúlveda nació en Santiago el 5 de diciembre de 1886; sus padres fueron Onofre Pinto -de raigambre radical- y Sabina Sepúlveda; cursó sus estudios primarios en un colegio de la calle San Isidro (tres años), y luego prosiguió su enseñanza secundaria en el Liceo de Isabel Le Brun de Pinochet (seis años).

Obtuvo el grado de bachiller en Humanidades -prueba que se daba al egresar de la educación secundaria- en 1902. Ello le permitió ingresar al Instituto Pedagógico de la Universidad de Chile al año siguiente. Allí estudió Pedagogía en Castellano, de acuerdo a sus intereses y gran afición a la lectura, que la tenía desde pequeña; egresó en 1905 junto a otras dos mujeres.

En 1906 contrajo matrimonio con el profesor y futuro ministro de Estado, militante radical, Guillermo Labarca Huberston, de quien adoptó sus dos apellidos, considerando las desavenencias que mantuvo con su familia, especialmente su padre, por sus posturas demasiado progresistas para la época. Ese mismo año, inició su labor de educadora en la Escuela Normal $N^{\circ} 3$ de Niñas de Santiago, donde ingresó como subdirectora, recién titulada; ello fue posible no sólo por sus méritos sino que por tener el apoyo de su marido, persona importante y conocida en el medio. En 1909 impartió clases de Castellano en el Liceo $\mathrm{N}^{\mathrm{o}} 2$ de Niñas de Santiago, año en el que participó, junto a otros educadores, en la fundación de la Sociedad Nacional de Profesores.

En 1910 viajó a los Estados Unidos, acompañada de su esposo, para perfeccionarse en el Teacher's College de la Universidad de Columbia en Nueva York, en donde conoció a Dewey y su pensamiento -el cual será su inspirador educacional a lo largo de su vida académica-; en 1912 se especializó en educación escolar en la Universidad de La Sorbonne en Francia.

En 1916, ya de regreso en Chile, fue designada directora del Liceo de Niñas $\mathrm{N}^{\circ} 5$ Rosario Orrego de Santiago ${ }^{2}$. En esa época ya mostraba un notorio carácter liberal, 
independiente y decidido, muy lejana a la vida de la simple mujer de comienzos de siglo en Chile.

En 1917, entre las mujeres laicas de las capas medias, con inspiración en los Readings Clubs de los Estados Unidos, se formó el Círculo de Lectura. En su fundación y directiva aparece Amanda Labarca, militante ya del Partido Radical, quién dirigió el periódico del Círculo, Acción Femenina, que tuvo destacada participación en la lucha por la obtención del voto femenino. Del Círculo de Lectura se desprendió, en 1919, el Consejo Nacional de Mujeres. Participaban en él, entre otras, Amanda Labarca y Celinda Reyes.

El grupo de mujeres del Consejo presentó en 1922 un proyecto sobre derechos civiles, políticos y jurídicos, iniciando gestiones que culminarán en 1925 con el Decreto Ley conocido como Ley Maza (por el senador José Maza), que restringe en el Código Civil las atribuciones de la patria potestad de los padres, en favor de las madres; se habilita a las mujeres para servir de testigos y se autoriza a las casadas para administrar los frutos de su trabajo. Fueron apoyadas por Pedro Aguirre Cerda, abogado, educador, Ministro de Estado, líder radical y futuro Presidente ${ }^{3}$ y Arturo Alessandri, entonces Presidente de la República.

En 1918 fue enviada a Estados Unidos por el gobierno para realizar un profundo diagnóstico sobre el sistema escolar de ese país.

En 1931fue nombrada Directora General de Educación Secundaria. Su labor fue próspera en actividad: continuó con el proyecto de experimentación educacional -inspirada en los principios de la Escuela Nueva en la persona de Dewey (Caiceo, 1995)- iniciado en 1929, lo que derivó en la fundación, el 28 de marzo de 1932, del Liceo Experimental Manuel de Salas, el cual estaba presidido por un Consejo integrado por ella misma, Irma Salas, Guillermo Mann, Darío Salas y Arturo Piga. Este Liceo pasó a depender de la Universidad de Chile en 1942, como centro de experimentación pedagógica para la formación de los futuros docentes en su antiguo Instituto Pedagógico.

Paralelamente a su labor en el sistema escolar, en 1922 obtuvo el cargo de Profesora Extraordinaria de Psicología, en la Facultad de Filosofía, Humanidades y Educación de la Universidad de Chile, luego de rendir el examen de suficiencia, convirtiéndose en la primera mujer latinoamericana en ejercer una cátedra universitaria. Habiendo iniciado su carrera universitaria como profesora del curso de Psicología, a fines de 1923, fue ascendida al grado de profesora ordinaria de Filosofía; es decir, miembro activo de la comunidad académica.

En 1932 pasó a integrar el Consejo Universitario, cargo que desempeñó por un año, para luego ser nombrada Delegada del Presidente de la República al Consejo Universitario, alta distinción que desempeñó hasta 1952. Su labor en la Universidad de Chile se extendió hasta diciembre de 1955, cuando jubiló por segunda vez. En 1963, a la edad de 77 años, fue distinguida con la calidad de Profesora Emérita de la Facultad de Filosofía y Educación de la Universidad de Chile, el grado académico más importante entregado a los profesionales más destacados. Al año siguiente fue distinguida como Miembro Académico de la Facultad de Filosofía y Educación de la Universidad de Chile, y en 1969 de la Academia de Ciencias Políticas, Sociales y Morales del Instituto de Chile. En su honor, al 
año siguiente de su muerte (1976) se creó la Medalla al Mérito Amanda Labarca, la cual se entrega a mujeres destacadas en el ámbito educativo.

También tuvo una importante labor diplomática cuando en el gobierno radical de Gabriel González Videla (1946-1952) fue nombrada embajadora como representante de Chile ante las Naciones Unidas.

Falleció en Santiago, el 2 de enero de 1975, a los 88 años de edad. Su legado aún permanece vigente en múltiples publicaciones en favor de los derechos de la mujer y sobre temas de educación, tal como se indicará más adelante (http://www.memoriachilena.cl/ temas/ dest.asp ?id=biografiaamandalabarca).

Su antiguo jefe, el ex rector de la Universidad de Chile, Juvenal Hernández, la describió en 1975 como sigue:

"Es una de las mujeres de más talento que ha producido este país... fue historiadora de la educación, gran maestra, profesora de Filosofía y de Psicología, escribía en la prensa permanentemente, intervenía en el Partido Radical, recibía en su casa. No había profesor eminente que llegara a Chile que no estuviera en la tertulia de Amanda Labarca... Es una mujer extraordinaria. Yo espero que la historia de esta mujer tendrá que hacerle justicia en la forma que merece" (http://www.memoriachilena.cl/602/w3article-755.html\#presentacion).

\section{3.- Sus escritos literarios, la mujer y la educación}

a) Contexto histórico, educacional, cultural y político a fines del siglo XIX en Chile

Afianzada la República al finalizar el primer gobierno pelucón de Prieto (18311841), comienzan a llegar al país una serie de escritores, educadores y políticos de otros países latinoamericanos que no aceptaban los caudillismos allí existentes o porque veían que en Chile podían desarrollar mejor sus intereses intelectuales. Es así, como arriban personalidades como Andrés Bello, venezolano, Domingo Faustino Sarmiento y Federico Álvarez de Toledo, argentinos y varios más. También llegan personalidades europeas, invitadas por el gobierno de Chile; entre ellos cabe destacar a los franceses Claudio Gay y Ambrosio Lozier; los españoles José Joaquín de Mora, Andrés Antonio de Gorbea y José León Cabezón; el polaco Ignacio Domeyko. Al igual que esas personas que traían ideas progresistas para la época, comenzaron a llegar las ideas europeas ligadas a la masonería y a pensamiento libertario; todo ello fue conformando lo que pasó a llamarse el laicismo. Producto del nuevo ambiente intelectual reinante, surge en el país el movimiento literario e intelectual, conocido como la generación de 1842; entre ellos, liderado por José Victorino Lastarria, se destacan Francisco Bilbao, Santiago Arcos, Salvador Sanfuentes, José Joaquín Vallejos, Antonio García Reyes, Eusebio Lillo, José Ramírez Rosales, Manuel Caro y muchos otros, de nacionalidad chilena (Celis, 2015). En este grupo también hubo argentinos, como Domingo Faustino Sarmiento y Juan Bautista Alberdi (Caiceo, 2013b).

A partir de este grupo se forma la "Sociedad de la Igualdad" en 1850, teniendo como base el "Club de la Reforma"; sus líderes son Santiago Arcos y Francisco Bilbao; 
asumen un liberalismo más radical, planteando una verdadera transformación revolucionaria de la sociedad para dar paso a una nación de hombres libres; este grupo de intelectuales, por primera vez, buscan alianzas con sectores populares (http://www. memoriachilena.cl/602/w3-article-94755.hmtl).

Paralelamente a lo anterior y con participación de varios de los nombres mencionados, en el ámbito educativo surgen tres importantes instituciones señeras de la educación laica chilena, como obras del estado y en función de su misión de preocuparse de la educación pública. En efecto, en 1842 se fundan la Universidad de Chile y la primera Escuela de Preceptores, dirigidas por Andrés Bello y Domingo Faustino Sarmiento, respectivamente. La base de la universidad fue la Real Universidad de San Felipe, fundada durante la colonia (1747).

El Rector Bello, en el discurso inaugural del inicio de las actividades de la Universidad de Chile, pronunciado el 18 de septiembre de 1843, indicaba:

"Con la asistencia del consejo, con la actividad ilustrada y patriótica de las diferentes facultades; bajo los auspicios del gobierno, bajo la influencia de la libertad, espíritu vital de las instituciones chilenas, me es lícito esperar que el caudal precioso de ciencia y talento, de que ya está en posesión la Universidad, se aumentará, se difundirá velozmente, en beneficio de la religión, de la moral, de la libertad misma, y de los intereses materiales".

"La Universidad, señores, no sería digna de ocupar un lugar en nuestras instituciones sociales, si (como murmuran algunos ecos oscuros de declamaciones antiguas) el cultivo de las ciencias y de las letras pudiese mirarse como peligroso bajo un punto de vista moral, o bajo un punto de vista político. La moral (que yo no separo de la religión) es la vida misma de la sociedad; la libertad es el estímulo que da un vigor sano y una actividad fecunda a las instituciones sociales" (Bello, 1843: 5).

En estos dos pasajes del Discurso, se percibe el espíritu profundamente humanista de Andrés Bello, unido a su deseo de cultivar la ciencia, uniéndola con la moral y la religión (Caiceo, 2013b).

La fundación de esta primera universidad pública en el país es un hito fundamental en la historia de la educación del siglo XIX y en el nacimiento de la clase profesional en el país. No obstante, el acceso a la instrucción universitaria estuvo vedado para la población femenina la mayor parte del siglo XIX, periodo en el cual aquella contaba con escasas alternativas educativas (http://www.memoriachilena.cl/602/w3-article-755.html\# presentacion).

Por su parte, el Ministro de Instrucción Pública, Justicia y Culto, Manuel Montt el 18 de enero de 1842 dicta el decreto, que crea la primera Escuela de Preceptores ${ }^{4}$, y en art.1 señala: Se establece en Santiago una escuela normal para la enseñanza e instrucción de las personas que han de dirigir las escuelas primarias en toda la extensión de la República" (citado por Caiceo, 2014: 191).

A su vez, en su Art. 2, se indica: 
"se enseñarán los ramos siguientes: leer y escribir con perfección y un conocimiento completo de los métodos de enseñanza mutua y simultánea; dogma y moral religiosa; aritmética comercial; gramática y ortografía castellana; geografía descriptiva; dibujo lineal; nociones generales de historia y particulares de la de Chile" (Idem: 191/192).

Esta Escuela fue inaugurada el 14 de junio de 1842, con sus primeros 28 alumnos; fue ubicada en un edificio cerca de la Plaza de Armas de la capital. En 1845 se transformó en internado y se ubicó en una construcción al lado de la Quinta Normal.

Sarmiento publicó en Chile una de sus principales obras pedagógicas De la Educación Popular (Santiago, Imprenta de Julio Belin y Compañía, 1849), en la cual expone su proyecto de escuela pública, gratuita y laica; en un Anexo del libro coloca un Proyecto de Ley de Instrucción Primaria, el cual sirvió de base para la ley definitiva aprobada en 1860, siendo Presidente Manuel Montt (1851-1861); debido a ella el estado se hacía responsable de ese nivel educacional para todos los niños y niñas del país.

La tercera institución importante fue la Escuela de Artes y Oficios -EAO- ${ }^{5}$, creada por decreto supremo del Presidente Manuel Bulnes Prieto (1841-1851) y, manteniéndose como Ministro del área, Manuel Montt Torres el 6 de julio de 1849. Su primer Director fue, también extranjero, el ingeniero y pedagogo francés Jules Jariez. Comenzó sus actividades en el barrio Yungay (calles Catedral con Chacabuco). En 1886 se inició la definitiva sede en la calle Ecuador, la cual aún existe y es considerada monumento nacional desde el primer centenario de su fundación. Los estudiantes recibidos en el siglo XIX eran personas que habían cumplido su educación primaria y allí eran formados en un oficio, egresando con el calificativo de "aprendices". Las primeras especialidades eran herrería, carpintería, mecánica y fundición. En 1912 se crearon los grados técnicos, post enseñanza secundaria y desde la década del 60 del siglo pasado se crearon las ingenierías de ejecución (Celis, 2015; Muñoz et al., 1987).

Por su parte, la educación de la mujer en Chile tuvo menos expresión que la masculina durante el siglo XIX. Sin embargo, para tener maestras preparadas para las pocas escuelas de niñas existentes, se fundó, por parte del estado, en el gobierno de Manuel Montt (1851-1861), la primera Escuela de Preceptoras ${ }^{6}$ el 26 de agosto de 1853; comenzó a funcionar al año siguiente. Para ello, solicitó a las Monjas del Sagrado Corazón que llegaran a Chile con esa misión (Egaña et al., 2003).

La Congregación del Sagrado Corazón o las conocidas como "monjas inglesas" llegan al país a cargo de Anna du Rousier. Establecen en el país tres tipos de establecimientos educacionales: Para la élite, un colegio pagado con internado que ayudaba a pagar el tercer tipo de escuela; la normal ya mencionada para formar maestras; durante el siglo XIX formaron 1980 educadoras; una escuela gratuita. En estos establecimientos no sólo se enseñaba el rol de la mujer en la sociedad sino que se desarrollaba tanto el aprendizaje para las tareas domésticas de la mujer como el conocimiento intelectual, al igual que el que recibían los hombres. En el colegio los conocimientos entregados eran similares a los del Instituto $\mathrm{Nacional}^{7}$, con planes de estudio muy parecidos. La educación integral de las futuras madres y ciudadanas del país era integral (De la Taille, 2012).

Durante gran parte del siglo XIX la mujer tenía como rol ser buena madre y buena esposa, herencia de la colonia; por lo mismo se la preparaba sólo en instrucción básica y en labores del hogar en escuelas primarias. Sin embargo, la fundación de la primera Escuela 
de Preceptoras y de Liceos para mujeres por instituciones privadas comenzó a cambiar la situación. El hecho más relevante fue las cartas que enviaron reiteradamente dos directoras y dueñas de Liceos Femeninos, Antonia Tarragó González -quien en 1864 había fundado el colegio "Santa Teresa"- e Isabel Lebrun de Pinochet -quien en 1875 fundó el "Colegio de la Recoleta" para mujeres, más conocido como "Liceo Isabel Le Brun de Pinochet" ${ }^{8}$ - al Consejo de Instrucción Pública, con el objeto que sus alumnas egresadas pudieran ingresar a la Universidad de Chile, situación vedada hasta entonces; la primera petición fue realizada en 1872. Al comienzo no se les hizo caso y hubo reacciones muy negativas de personas de mentalidad conservadora frente a tal petición. Pero la insistencia de la segunda de ellas, llevó a que finalmente en el gobierno de Aníbal Pinto (1876-1881), el Ministro Miguel Luis Amunátegui Aldunate, Ministro de Justicia, Culto e Instrucción Pública, dictó el Decreto -que se le conoce por su apellido- el 6 de febrero de 1877, que permitió que las mujeres pudieran acceder a la universidad (Sánchez, 2006). Textualmente, señala: "Se declara que las mujeres deben ser admitidas a rendir exámenes válidos para obtener títulos profesionales, con tal que se sometan para ello a las mismas disposiciones a que están sujetos los hombres" (Archivo Universidad de Chile: 34 en Sánchez, 2006).

De acuerdo a lo anterior, el mencionado Decreto considera expresamente tres puntos: (i) Conviene estimular a las mujeres que hagan estudios serios y sólidos en la Universidad; (ii) Puedan ejercer con ventaja alguna de las profesiones denominadas científicas; (iii) Importa facilitarles los medios que puedan ganar la subsistencia por sí mismas (http://www.dibam.cl/Recursos/Contenidos/Museo\%20Hist\%C3\%B3rico\%20Na cional/archivos/Decreto\%20Amun\%C3\%A1tegui.pdf). Las primeras tituladas universitarias como médicos cirujanos fueron Eloísa Díaz y Ernestina Pérez

En este contexto, surge la idea de fundar liceos femeninos fiscales; el primero de éstos será el Liceo $N^{\circ} 1$ de Valparaíso (1891) y el segundo el Liceo Nº1 de Santiago (1894).

\section{b) La mujer y la educación presentes en la literatura de Amanda Labarca}

Para desprender y entender su pensamiento educativo hay que conocer sus principales obras, las cuales versan sobre literatura, diplomacia, didáctica y pedagogía, historia de la educación, filosofía y política educacional. A partir de sus textos se puede concluir que la preocupación permanente de Amanda Labarca fue la educación de su país, a partir de sus propias reflexiones y de lo que estudió y conoció en sus viajes de estudio y diplomacia. Su interés está en hacer que la educación en Chile sea más democrática, es decir, se universalice, especialmente la educación secundaria; que haya experimentación educativa en el país para mejorar las metodologías de enseñanza; que los estudiantes reciban una sólida formación moral, libertaria y laica. Para comprender mejor lo anterior recurre a la historia de la educación -tanto en Chile como en Estados Unidos- y aspira a que gracias a la educación la sociedad se fortifique en los ideales democráticos, sea más colaboradora y que sus miembros, al estar más educados, sean agentes de progreso en fraternidad social, cooperativa y solidaria y alcancen un desarrollo físico y moral íntegro. Postula que el fin de la educación es la consecución de la felicidad colectiva. Como se puede desprender de lo anterior, la pedagogía de la escuela nueva, especialmente de Dewey, está claramente presente, como, al mismo tiempo, sus principios masónicos.

Amanda Labarca debe ser considerada como una de las mujeres más sobresalientes del siglo XX. Mujer de ideales progresistas, democráticos y laicos, por ende, de tendencias 
radicales; aspiró y ayudó al progreso de una educación para todos, así como por una sociedad igualitaria (Caiceo, 2013 ${ }^{\mathrm{a}}$ ).

Este trabajo se centrará especialmente en su labor como crítica literaria y escritora, preocupándose especialmente del rol de la mujer en la sociedad. Su estilo literario, como buena profesora de castellano, queda claramente reflejado en la siguiente frase; también su espíritu maternal: “'Oh, momento divino, detente! ¡Creatura de mis entrañas, susurra la madre a su pequeñuelo, quédate pequeñito; no crezcas, que yo pueda arrullarte siempre entre mis brazos!" (Labarca, 1947: 10).

Su preocupación literaria fue a muy temprana edad. A los 21 años dictó una Conferencia en la Universidad de Chile, titulada "La novela castellana hoy" (28 de agosto de 1907); posteriormente en 1909 se publicó como Impresiones de Juventud. En ese trabajo se lee:

“Os habéis detenido a pensar alguna vez en que la juventud posee una gran fuerza de atracción hacia toda otra juventud y que los espíritus jóvenes se buscan a través de las distancias para unir sus entusiasmos y romanticismos? Estas páginas no tienen más razón de existir que tal fuerza. Me he sentido atraída con irresistible empuje a estudiar la nueva literatura hispánica: primero, porque eran jóvenes quienes la cultivaban; después, porque ellos hablaban la misma lengua nuestra y en el cultivo de la misma habla, trabajaban" (Labarca, 1909: 1035/1036).

Más adelante, agrega:

"Son, pues, estas páginas producto de amor, no de gazmoñería; de deseo de dar a conocer el alma de los otros, antes que de hacer propia una obra de arte; son las repercusiones que en mis veinte años han tenido los lirismos fervorosos y las torturadas psicologías de los poetas y novelistas jóvenes; son la onda acústica debilitada por el eco; la admiración que despierta toda cosa bella" (Labarca, 1909: 1036).

El estilo de su prosa es directo; a veces lírico y siempre con un afán didáctico. A su vez, como se verá más adelante, la mayoría de sus escritos posteriores siempre versarán sobre su preocupación central: los derechos de la mujer, especialmente el derecho a la educación en igualdad de condiciones que el varón y el derecho al sufragio; ellos corresponden a Ensayos, según Rubio (1999); esos escritos son expresados y defendidos con rigor y vehemencia; se presentan ideas pioneras en Chile. La lógica de sus escritos ensayísticos se puede sintetizar en que para poder votar bien, la mujer debía primero instruirse; todo ello, a su vez, con la finalidad de democratizar más el país, siguiendo lo planteado por Dewey; en el fondo su posición desde el punto de vista literario se asume, por parte de ella, políticamente, es decir, tendrá trascendencia en las políticas públicas futuras en favor de la mujer. Por otra parte, ella, primero se volcó a España por su título original, pero cuando visitó Estados Unidos se deslumbró con la cultura y educación de ese país y sus escritos posteriores tendrán aquello como modelo.

Existen, sin embargo, además de los ensayos, otras dos vertientes, según Rubio (1999): (i) Reflexiones íntimas, tipo diario personal; ello está claramente presentado en Desvelos en el alba (1945); relata lo que sucede en su interior, especialmente en sus zonas más vulnerables como mujer, la cual piensa y actúa de manera independiente respecto a las 
normas existentes, pues desea dedicar su vida a un ideal que en ese momento está vedado a la mujer; por lo mismo, se encuentra con diversos obstáculos, que la llevan a la duda, desesperanza y depresión. Algunos trozos de la obra son decidores al respecto: "Tras días amargos, vuelve a alucinarme la sirena de las cuencas vacías. Vivir es un esperar estéril, es morir lentamente. ¿Por qué no tarjar de un golpe estas horas que nos llevan incesantemente hacia la vejez, la ruina, la definitiva renunciación?" (Labarca, 1945: 107). Luego agrega: "Con qué dulcedumbre van escurriéndose las horas! En la vorágine que Chile es hoy, me parece que mi hogar y yo hemos sido lanzados a un lejano remanso, a donde los ecos del tumulto llegan amortecidos... iQué distinta que soy de lo que fui hace apenas dos o tres años"(Labarca, 1945: 111-112). Realmente en esta obra entrega lo que está sucediendo en lo más íntimo de su ser; muestra su yo interior; por lo mismo, escribe: "Me parece que estuviera pisando en una tembladera en la cual me hundiera cada minuto más... Mis ímpetus, mi desafiante actitud interior, ¿dónde están? ¿Es esto envejecer? (Labarca, 1945: 118-119). Esta obra muestra su interioridad, pero la autora se encuentra en una actitud tan pesimista que pareciera que no es educativa; sin embargo, por otra parte, revela su humanidad, lo cual sí es pedagógico.

(ii) Narrativa ficcional, la cual se expresa en dos novelas y varios cuentos. Las novelas son En tierras extrañas (1915) y La lámpara maravillosa (1921); los cuentos son breves y están juntos con el nombre de Cuentos a mi señor (s/f). En su novela más larga, relata la historia de un joven, Carlos del Solar, oriundo de La Serena, quien viaja a estudiar a Nueva York, enviado por su padre, un rico terrateniente. Al comienzo, el joven tiene mucha desconfianza con esas tierras, pero al encontrar el amor en Eva Wright comienza a apreciar los valores de la cultura y de las personas que la rodean. De esta forma se convierte en un hombre decidido a emprender una acción renovadora en su país. ¿No es acaso esta narrativa ficticia un reflejo de lo que hará Amanda Labarca al volver de sus estudios en Estados Unidos?

Por otra parte, en sus obras consideradas ensayos, respecto al feminismo, señala:

"Entre estas mudanzas violentas y penosas que obligan a revisar conceptos y actitudes espirituales que han calado muy hondo en el subconsciente racial se halla el feminismo. Le vemos como realización casi plena entre los pueblos norsos y sajones; cuestionado entre los latinos; vituperado por los que ayer proclamaron las dictaduras nacifacistas. La teoría es idéntica; la respuesta del medio, diversa" (Labarca, 1947: 16-17).

A su vez, se refiere al programa que establecieron en 1848 en Estados Unidos las primeras mujeres preocupadas del tema en un congreso, Isabel Cady Stanton y Lucrecia Mott. En su momento apareció como

\footnotetext{
"un atrevimiento revolucionario: (i) Iguales derechos de educación para niñas y varones; (ii) Derecho de la mujer casada para testar; (iii) Derecho de la mujer casada para administrar sus propios bienes; (iv) Derecho de la mujer casada para percibir y administrar sus salarios, sueldos y emolumentos; (v) Derecho para preparase para ejercer profesiones y facultad de ejercerlas; (vi) A igualdad de trabajo, igual salario que el hombre; (vii) Igual derecho a sufragio" (Labarca, 1947: 34-35) .
} 
Por estos aspectos luchó Amanda Labarca a lo largo de su vida; incluso los puntos i y $\mathrm{v}$ ya se habían alcanzado en Chile 9 años antes que naciera, gracias al Decreto Amunátegui. Por el vii y mejor educación y formación para la mujer fue su preocupación constante. Ella explícitamente reconoce que "nuestro país, abrió las puertas de la Universidad a la mujer en 1877, cuando aún no lo hacían la mayor parte de los países latinos" (Labarca, 1947: 85).

$\mathrm{Su}$ actividad feminista se inició cunado visitando establecimientos escolares femeninos, daba charlas de literatura a estudiantes, replicando lo que ella hacía con sus propias alumnas:

\begin{abstract}
"Algunas de estas conversaciones-conferencias fueron publicadas, como por ejemplo: 'Mujeres Modernas' (1913), que fue una conferencia que dictó para una graduación en el Santiago College, en la cual explica cómo las transformaciones sociales y políticas amplian los espacios para la mujer en la sociedad" Quiroz et al., 2010:5).
\end{abstract}

Por otra parte, al leer sus principales textos que pueden considerarse literarios, están presente en ellos tres aspectos fundamentales: (i) La igualdad entre hombre y mujer -hoy se diría igualdad de género-; (ii) El derecho a la educación, especialmente de la mujer y los analfabetos; (iii) Los derechos políticos para la mujer. De ello, se desprende que su mayor preocupación a lo largo de su vida es el feminismo -usando sus propias palabras-. A continuación se presenta en sus textos originales su pensamiento al respecto.

\title{
- La igualdad entre hombre y mujer
}

En relación a este aspecto, hace presente que el cristianismo no hace distinción entre hombre y mujer (San Pablo a los Gálatas 3,28); sin embargo, el cristianismo influido por el derecho romano estableció, cuando se consolidó como religión oficial del Imperio Romano, la potestad marital y la mujer sólo "podía ejercer sus derechos a través de su representante legal: el hombre”. Esta idea la consagró Andrés Bello en el Código Civil de Chile. Por lo tanto, cambiar esa idea a lo largo de la historia "ha parecido ofensa máxima a un régimen secular, locura, indignidad, falta de pudor o de modestia, atentado contra las buenas costumbres" (Labarca, 1947: 18). Pero ella, indica: "No son iguales, pero si, equivalentes, porque son idénticamente necesarios a la vida y al desarrollo de la raza. Son equivalentes, por lo tanto, es injusta cualquiera ley que conceda derechos a unos en desmedro de los otros" (Labarca, 1934: 54). En otro texto señala con fuerza que se han cometido muchos errores al considerar a la mujer como algo inferior:

\footnotetext{
"Las religiones de Europa Occidental reafirmaron las obligaciones diversas de los componentes de la familia humana: 'Compañera te doy y no sierva'. ¿Por qué esta admonición? Con claridad se subentiende que asignaban oficios distintos a cada uno. Oficio, función tratamiento y rango, luego aparecen diversificados. Duros, impios, sin consideración para los débiles entre los que se contaban las mujeres" (Labarca 1970: 8).
}

Continuando con su análisis sociológico interpretativo de la situación del hombre y la mujer, enfatiza el rol de la familia, como base del conjunto social; incluso critica a quienes no ven así la sociedad; al respecto, dice: 
"Tanto hombre como mujer no actúan solos. Están inmersos en un conjunto social compuesto social compuesto de infinitos círculos concéntricos que van desde la familia bipersonal hasta la humanidad. Y tal como para examinar la situación del varón, hay que detenerse en la clase de actividad que se le exige, asimismo el resto análisis de la condición femenina no puede separarse de ese núcleo formidable que es la familia, entendiendo por ésta a la que permite la convivencia de varón, mujer e hijo. Extraer a la niña o la cónyuge de este conglomerado, estudiándolas como si tuvieran existencia aislada, es principiar por reducir el horizonte del problema, pecado en que han caído más de un sociólogo y muchísimas feministas" (Labarca 1970: 12).

Sobre la situación histórica del hombre y la mujer, también tiene algo que añadir:

"De acuerdo con la forma de vida que les imprimía el medio, macho y hembra, hicieron frente a toda clase de enemigos. La función y la importancia de la mujer variaron, pero siempre fue complementaria a la del varón. De otro modo no habrían sobrevivido. iIguales, imposible! Diferentes, complementarios, equivalentes, eso son. Además tan responsables el uno como el otro de la suerte de la especie" (Labarca 1970: 16).

Sobre el mismo punto agrega:

“... La niña se casaba a los 13 ó 14 años con un varón que generalmente la aventajaba en 10 o más. Y pasaba de la calidad de menor bajo la potestad paterna a la de menor también en su nueva casa. La tradición no permitía por motivo alguno el divorcio con disolución de vínculo. Si, por desgracia, el marido la maltrataba, la hería, la abandonaba, había que resignarse. ¡Tal era su suerte..." (Labarca, A, 1951: 109/110).

Esto último revela en la situación de indefensión en que se encontraba la mujer, lo cual era imprescindible cambiar, pues la mujer es un ser humano igual que el hombre y, por lo mismo, debe tener los mismos derechos.

Más adelante, sobre la pareja humana, reflexiona:

“... desde que tenemos noticias, la pareja humana es quien ha prolongado la especie. Hombre y mujer, solitarios al comienzo de los siglos, pudieron engendrar monstruos. Que nosotros sepamos, inseparablemente unidos, aprendieron a engendrar y criar hijos normales, sin ayuda de ningún Proteo, de ningún Cíclope, ni hipogrifos, ni sirenas" (Labarca 1970: 15).

Pero el avance del reconocimiento de los derechos de la mujer y la lucha que ellas mismas dieron, continuó. En efecto, la organización de las mujeres en diversos eventos -el congreso de 1848 en Estados Unidos, ya mencionado, la Conferencia de Chapultepec, la Conferencia de San Francisco, entre otros- se presionó para que en la "Carta de la Naciones Unidas" de 1948 se incluyeran tres recomendaciones que han permitido posteriormente

"la reestructuración del mundo: ... Art 3: Fomentar y alentar el respeto por los derechos humanos y por las libertades fundamentales de todos, sin distinción de raza, sexo, lengua o religión... Art. 8: Las Naciones Unidas no establecerán restricciones en la elegibilidad de hombres y mujeres destinados a participar en 
cualquiera capacidad y condiciones de igualdad... Art. 13: Promover la cooperación internacional en los campos económicos, sociales, culturales, educacionales y de salubridad, y ayudar a la realización de los derechos humanos y las libertades básicas para todos, sin distinción de raza, sexo, lenguaje o religión" (Labarca, 1947: 59-60).

Amanda Labarca reconoce el avance que hacia la mitad del siglo pasado había tenido la mujer en Chile en cuanto a igualdad de derechos: "Oscila la mujer de hoy entre dos órbitas: la del hogar y la del mundo, la participación en cuyas múltiples actividades desconocieron nuestras abuelas" (Labarca, 1947: 158). En otro texto, describe la nueva situación de la mujer, una vez que se alcanza muchos de sus derechos; es la realidad de la década del 60 del siglo pasado que la autora describe:

"El hogar de hoy, señores, no es el que conocisteis en vuestra juventud. En el actual, la mujer siente que es su derecho el de escribir en el cuaderno de su vida el poema propio, el que traduzca sus aspiraciones, el que pueda elevarla, si lo desea, hasta la conquista del cosmos. 'El único fin de la existencia humana -ha dicho Fichte -no es lograr el cielo ni el de hundirse en el infierno, es el expresar la humanidad que llevamos en nosotros hasta la mayor perfección que nos sea dable alcanzar"' (Labarca 1970: 17).

A modo de conclusión sobre la situación de la mujer en la segunda mitad del siglo $\mathrm{XX}$, hace una reflexión que más parece una queja, pues percibe que el ímpetu inicial por lograr sus derechos ha decrecido:

“... en América del Sur como en la Norte y en algunos países europeos, se ha advertido, sobre todo al final de la década del 50, un descenso en el ímpetu de las huestes femeninas para hacer uso de sus nuevos derechos. No han ido a golpear a las verjas del parlamento, no fueron ellas las protagonistas, fueron sus madres. La hija se acoge al regazo materno y se pregunta si ha valido luchar tan amargamente" (Labarca 1970: 13).

\section{- El derecho a la educación, especialmente de la mujer y los analfabetos}

Para la autora, el tema de la educación femenina es complejo, "porque está ligado al futuro de la raza, de la familia, del hogar, a las necesidades de la nación y de la sociedad, y, además, debe contemplar las necesidades individuales de la mujer que necesita aprender a bastarse por sí misma, espiritual y económicamente" (Labarca, 1951: 25).

Ella explícitamente reconoce, en todo caso, que

"nuestro país, abrió las puertas de la Universidad a la mujer en 1877, cuando aún no lo hacían la mayor parte de los países latinos de Europa como de América; graduó sus primeras médicas en 1886; estableció una red de liceos públicos y gratuitos desde 1894" (Labarca, 1947: 125).

En síntesis, la autora piensa que una educación adecuada para la mujer, en su infancia y adolescencia, beneficiará a la larga a los hijos de la misma, pues siendo más culta, preparada y equilibrada podrá ayudarlos mejor en su formación (Labraca, 1947). 


\section{- Los derechos políticos para la mujer}

En relación a los derechos políticos expresa que "deben ser ejercidos por todos, sin distinción de sexo, de raza, de situación económica y aún del conocimiento rudimentario del alfabeto" (Labarca, 1947: 84). En otro texto, señala en relación a los países sudamericanos:

"Desde su independencia se les ha gobernado sin parar mientes en que los procederes democráticos ajustasen o no a la realidad. Si tal régimen tiene por base el concepto de fundamental igualdad de hombre a hombre, y el gobierno de los demás, es evidente que nunca han conocido una genuina democracia. Jamás han estado elegidos por la mayoría, ya que se apartaba de ella a la gran masa de analfabetos y a las mujeres. Si algo puede enrostrarse amargamente a los congresales, ejecutivos y caudillos es que desde 1810 no hayan dedicado su empeño máximo en transformar en ciudadanos de verdad al enorme cuerpo de semi-civilizados, que constituyen la estrada básica de nuestra realidad sociedad, y les hayan permitido vegetar sin ninguna tradición de democracia" (Labarca, 1934: 51).

También se refiere a Chile específicamente:

"Así como parece de toda justicia y conveniencia el sufragio político femenino, podría dudarse de su oportunidad si sus adeptas no se preparasen para ejercitarlo. Esto es muchísimo más urgente que la dictación de la ley. Si desconocen los fundamentos del régimen republicano, si nunca han tratado de comprender las diferencias de doctrinas y métodos entre los partidos, si ignoran los problemas de la economía nacional, las cuestiones que a diario han de afrontar municipios y gobiernos centrales, mal pueden pretender mejorar las condiciones existentes. Y si no están ejercitadas en la práctica de la asociación, les será muy difícil influir en la cosa pública" (Labarca, 1934: 54).

Hace también una crítica a los gobiernos: "El sufragio, a los capacitados, a los sensibles a sus responsabilidades, hombre y mujer, porque ambos sufren por igual los errores de la dirección política, los desaciertos económicos y los fardos tributarios" (Labarca, 1934: 53). Luego hace un análisis crítico de la concreción del derecho a sufragio: "El derecho al sufragio en igualdad de condiciones con el hombre se consiguió en la mayoría de las naciones occidentales. Sin embargo, persisten reductos hasta ahora inexpugnables" (Labarca 1970: 13).

Hay que tener presente que en Chile se estableció en la constitución de 1833 que podían votar sólo los hombres que sabían leer y escribir, mayores de 25 años y con una propiedad o capital equivalente. En 1874 se rebajó a 21 años la edad si los hombres eran casados y se mantuvo en 25 a los solteros. En 1888 se mantuvo la edad de 21 años para todos los hombres y que supieran leer y escribir; se eliminaron los otros requisitos. En 1934 se extiende el derecho anterior y en las mismas condiciones a las mujeres, pero sólo para votar en las elecciones municipales. En 1949 se eliminó la restricción anterior para las mujeres y podrán ejercer su derecho en cualquier elección. En 1967 se les dio el derecho a sufragar a los no videntes y en 1972 a los analfabetos (http://www.memoriachilena.cl/602/w3-article-3382.html). Amanda Labarca tuvo la dicha de ver concretada en hechos su lucha por los derechos políticos de la mujer y de los analfabetos antes de morir. 


\title{
- Fuente de inspiración
}

Ya se indicó en páginas precedentes que detrás de los planteamientos de Amanda Labarca se encuentra el pensamiento de John Dewey, en el sentido que reforzando la educación, se reforzará la democracia. Textualmente señala que "la democracia es cooperación y no subyugamiento" (Labarca, 1947: 144). Por lo mismo, subraya: "La obra de la república debería tender más y más a la incorporación a la verdadera democracia, del mayor número de hombres y mujeres, capacitándolas para comprender los problemas vitales del país y participar en ellos" (Labarca, 1934: 52).

Nuestra autora vivió las dos guerras mundiales y la guerra fría. Por lo mismo siempre estuvo muy preocupada por el futuro de la humanidad. Queda clara su posición al respecto, fundamentando cómo la humanidad debe enfrentar el futuro, con una posición humanista y valórica. Pareciera que lo que escribió en 1946 estuviera reflejando el mundo del siglo XXI. Ello se debe por su planteamiento profundamente humanista y, por lo mismo, trascendente. Dice al respecto:

\begin{abstract}
"Una nueva valoración de lo ético-social, una educación que nos habitúe a fraternizar más de verdad, aliviar mejor la miseria, la injusticia y el dolor; una educación que coloque al intelecto como medio y a la ética social como fin, que lejos de exaltar la soberbia egoísta nos induzca a considerarnos parte responsable de un conglomerado en que todos tienen derecho a recibir en justicia, a vivir en dignidad, a crecer en esperanzas. En estos instantes de inseguridad e inestabilidad mundiales, vale la pena meditar sobre estos problemas de vida y muerte para nuestra civilización, y preguntarnos si la clave de ellos no está en el corazón de cada uno de nosotros" (Labarca, 1947: 223).
\end{abstract}

Aunque parezca extraño en una mujer revolucionaria para su tiempo, en edad más avanzada hace una severa crítica a la nueva realidad existente:

"La libertad raya hoy en el libertinaje; la espontaneidad confundida con la desnudez; el lenguaje soez toma el sitio que antes ocupaba la buena educación, y ha reemplazado a las fórmulas de cortesía. Lo hippies, que han visto transcurrir su juventud en los campamentos soldadescos, intentan con éxito reemplazar esta antigua convivencia culta por la ruda y plebeya que han aprendido en el vivac. Ese es su modelo de vida" (Labarca 1970: 11).

La reflexión final está imbuida de su gran pasión, educar: "Conocimiento, concordia, amor es lo que tenemos que enseñar. Sobre todo a la generación joven" (Labarca 1970: 16/17).

\section{4.- Conclusiones}

No cabe duda de que la labor desarrollada en favor de los derechos femeninos a través de los escritos literarios de Amanda Labarca, objetivo de este trabajo -independiente de las acciones que también realizó en la misma línea-, fue relevante, especialmente que, gracias a ello, ayudó a promover políticas públicas en favor de que el estado de Chile se hiciera cargo de los derechos de la mujer, principalmente en el ámbito educacional y político. Esta labor la desarrolló teniendo presente los contextos sociales, históricos y políticos que se daban en su tiempo, pero pensaba que los problemas que existían a nivel 
de la pedagogía se explicaban por la descontextualización de las procesos educativos y, por lo tanto, lo más importante eran cambiar las políticas públicas en educación (Quiroz et al., 2010); logrado aquello, se iban a desencadenar los otros acontecimientos que era parte de su inquietud académica: logrando la educación de la mujer en los diferentes niveles del sistema escolar iba a posibilitar el cambio de mentalidad en la época, la mujer iba a poder acceder a sus derechos políticos real y responsablemente, todo lo cual, afianzaría mucho más la democracia en el país. En pro de lo anterior, fundamentalmente los ensayos aquí analizados, cumplieron eficazmente su intencionalidad final.

Toda persona es hija de su tiempo. En este sentido, Amanda Labarca supo interpretar las necesidades y problemas de su época y los abordó decididamente. Ahora bien, algunos se preguntan si ello fue original (Rojas, 2004); evidentemente que no fue suya la idea de preocuparse por los derechos de la mujer; era la inquietud del momento, pero ella supo -como ella misma relata la actitud del joven Carlos del Solar en Tierras extrañas a modo de analogía- en forma desafiante asumir la bandera del feminismo en Chile, tanto en su acción como en sus escritos, tal como se ha demostrado a lo largo de este trabajo; su originalidad radica en su actitud y acción permanentes a lo largo de toda su vida.

\section{4.- Fuentes de Consulta}

ARCHIVO UNIVERSIDAD DE CHILE (1987), volumen LII.

CAICEO, Jaime (1995). "Influencia Pedagógica de Dewey en Chile" en Estudios Paraguayos, Vol. XVIII, Nos. 1-2, diciembre 1990-1995. Asunción del Paraguay: Universidad Católica Nuestra Señora de la Asunción.

CAICEO, Jaime (2013a). "Amanda Labarca, Importante Educadora Feminista del Siglo XX en Chile". Ponencia presentada para el Simposio No 30 "Diálogo entre Educación, Género y Ciudadanía en Distintos Contextos Sociales Siglos XIX al XXI" en el Tercer Congreso Internacional del Conocimiento, titulado Ciencias, Tecnologías y Culturas. Diálogo entre las disciplinas del conocimiento. Mirando al futuro de América Latina y el Caribe, que se desarrolló entre el 7 y el 10 de enero en la Universidad de Santiago de Chile.

CAICEO, Jaime (2013b). "La enseñanza universitaria laica y gratuita versus la enseñanza particular y católica: un debate de ayer y de hoy en Chile" en Acta Scientiarum. Education, v. 35, n. 1, p. 89-95, Jan.-June, Maringá, Brasil.

CAICEO, Jaime (2014). "Influencia Educacional de Domingo Faustino Sarmiento en Chile" en Dos Puntas, $\mathrm{N}^{\circ} 10$, Universidad Nacional de San Juan (Argentina)-Universidad de La Serena (Chile), pp. 183-204.

CELIS, Luis (2015). Historia de la Educación en Chile: Siglos XVI al XIX. Santiago de Chile: Universidad de Los Lagos.

DE LA TAILLE, Alexandrine (2012). Educar a la Francesa: Anna du Roussier y el Impacto del Sagrado Corazón en la Mujer Chilena (1806-1880). Santiago de Chile: Ediciones Universidad Católica de Chile. 
EGAÑA, María Loreto; NÚÑEZ, Iván; SALINAS, Cecilia (2003). La Educación Primaria en Chile: 1860-1930. Una Aventura de Niñas y Maestras. Santiago de Chile: LOM ediciones- PIIE.

http://www.dibam.cl/Recursos/Contenidos/Museo\%20Hist\%C3\%B3rico\%20Nacional/arch ivos/Decreto\%20Amun\%C3\%A1tegui.pdf. Consultada el 14 de agosto de 2015.

http://www.memoriachilena.cl/602/w3-article-755.html\#presentacion. Consultada el 10 de agosto de 2015.

http://www.memoriachilena.cl/602/w3-article-3382.html. Consultada el 18 de agosto de 2015.

http://www.memoriachilena.cl/temas/dest.asp ?id=biografiaamandalabarca). Consultada el 10 de agosto de 2015.

http://www.memoriachilena.cl/602/w3-article-94755.hmtl). Consultada el 10 de agosto de 2015.

LABARCA, Amanda (1909). La Novela Castellana de Hoy" en Anales de la Universidad de Chile (1909). Santiago de Chile: Imprenta del Pacífico, pp. 1035-1037 Consultado el 17 de agosto de 2015 en http://www.memoriachilena.cl 1602/w3-article-98850.html.

LABARCA, Amanda (1915). En tierras extrañas. Santiago de Chile: Imprenta Universitaria.

LABARCA, Amanda (1934). ¿A Dónde va la mujer? Santiago de Chile: Ed. Extra.

LABARCA, Amanda (1945). Desvelos en el Alba. Santiago de Chile: Cruz del Sur.

LABARCA, Amanda (1947). Feminismo contemporáneo. Santiago de Chile: Ed. Zig-Zag.

LABARCA, Amanda (1951). Evolución Femenina en el Desarrollo de Chile en la primera mitad del siglo XX. Santiago de Chile: Ediciones de la U. de Chile.

LABARCA, Amanda (1970). Una Mujer enjuicia al tiempo. Discurso de Incorporación a la Academia de Ciencias Sociales, Políticas y Morales del Instituto de Chile. Santiago de Chile: Ed. Andrés Bello.

LA BIBLIA DE NUESTRO PUEBLO (2011). Bilbao, España.

MUÑOZ, Juan et al. (1987). La Universidad de Santiago de Chile. Santiago de Chile: Ed. USACH.

QUIROZ; Viola et al. (2010) Amanda Labarca y sus aportes innovadores para la educación en Chile del siglo XX. Santiago de Chile: UMCE en es.scribd.com/.../Amanda-Labarca-y-sus-aportes-innovadores-para-la....

ROJAS, María Teresa (2004). "Amanda Labarca: La participación femenina en la construcción de un discurso educativo" en Pensamiento Educativo, Vol. 34 (junio), Pontificia Universidad Católica de Chile: pp. 179-199.

RUBIO, Patricia (1999). Escritoras Chilenas. Volumen III: Novela y cuento. Santiago de Chile: Ed. Cuarto Propio.

SÁNCHEZ, Karin (2006). "El ingreso de la mujer chilena a la universidad y los cambios en la costumbre por medio de la ley 1872-1877" en Historia, vol. II, núm. 39, julio-diciembre, Pontificia Universidad Católica de Chile.

Santiago de Chile, octubre 2015. 
1 Artículo basado en la Ponencia presentada en el Simposio “Diálogos entre Literatura y Educación” en el IV Congreso Internacional Ciencias, Tecnologías y Culturas realizado en la Universidad de Santiago de Chile entre el 9 y el 12 de octubre de 2015.

2 En esa época era alumna del establecimiento Irma Salas, con la cual traba una importante amistad que durará toda la vida. La profesora Salas será también una importante educadora laica y seguidora de Dewey, con quien se doctoró en Estados Unidos. Fue la Presidenta de la Comisión que preparó la Reforma Gradual de la Enseñanza Secundaria en 1945 (Celis, Caiceo et al., 1992).

3 Fue elegido en 1938 con apoyo del Frente Popular (Radicales, Socialistas y Comunistas).

$4 \quad$ Futura Escuela Normal para hombres y la primera de 28 Escuelas Normales creadas posteriormente en diferentes ciudades del país. A la Primera Escuela, se le llamó Escuela Superior José Abelardo Núñez, en honor al gran educador chileno, reestructurador de la misma en la segunda mitad del siglo XIX (Caiceo, 2014).

$5 \quad$ En 1947 se transformó en la Universidad Técnica del Estado, con sedes en varias sedes de Provincias, y desde 1981 en Universidad de Santiago de Chile, reducida sólo a la capital.

6 Con el tiempo pasará a ser Escuela Normal Femenina y también se fundarán varias a lo largo del país. La necesidad de formación de maestras originó la creación de la Escuela Normal de Chillán en 1871 y de La Serena en 1874. Ambas escuelas fueron promovidas por la educadora Mercedes Cervelló (Celis, 2015).

7 Entidad pública fundada en 1813 por José Miguel Carrera. Institución señera de la educación pública y laica en Chile hasta el presente.

8 Como se indicó precedentemente, en este Liceo hizo su enseñanza secundaria Amanda Labarca.

Recebido: $\quad$ setembro-15 Aprovado: setembro-15 